\section{A BASIC factorial analysis of covariance program for three microcomputer families}

\author{
DAVID LIONELL DAWSON \\ University of South Dakota \\ Vermillion, South Dakota
}

Analysis of covariance (ANCOVA) is a nearly indispensable statistical technique for a variety of experimental designs, for example, for the analysis of data from nonequivalent groups designs, such as data produced through quasi-experiments (Cook \& Campbell, 1979). Rather than merely evaluating posttest data, ANCOVA allows for the evaluation of dependent variables relative to the initial condition of each subject in question, thus reducing subject-induced error variance and increasing the sensitivity and power of the statistical test. This is especially valuable when a within-subject design is not feasible and substantial variability of subjects is likely.

As an extension to the program made available by Galla (1984), a factorial (two-way) ANCOVA program is described here. Machine-readable versions for IBM PC and PC clones, Tandy Color Computer (version 1, 2, or 3), and Apple II-compatible machines are available.

Procedure. The two-way ANCOVA program requires a pair of scores (the dependent variable and covariate) drawn from each subject or assignment unit. The dependent variable is entered into the program first, followed by the covariate. These score pairs are segregated into variable and variable level groupings for data entry. The BASIC program allows for three different data entry methods, including fully prompted keyboard entry.

Program. The factorial ANCOVA program is available for IBM PC computers and clones with BASICA or GWBASIC, Tandy Color Computers (CoCos) with Extended Disk BASIC, or Apple II+ machines or close family members (the available disk was created with Apple II DOS version 3.2.1). The BASIC syntax common to all versions is universal enough so that the program can be easily converted to other machines with similar BASICs.

Both an analysis of variance and an analysis of covariance summary table are presented to the user, as well as adjusted and unadjusted cell means. The program has been verified for accuracy against data appearing in Winer (1971), Kirk (1982), Meyers (1979), and Howell (1982).

\footnotetext{
The author's mailing address is UNISYS Corporation, P.O. Box 500 MSE2127, Township and Union Meeting Road, Blue Bell, PA 19424.
}

Input. Data quantity and design size limits are flexible and set depending upon the design described to the computer during a session. Data may be read from the keyboard (with full prompts), from a standard ASCII disk data file (which can be created with any text editor), or from BASIC DATA statements. Disk file data should be formatted so that each data point appears on a separate line, followed by a carriage return and line feed (depending upon the machine).

Data are presented to the program with the dependent variable measure appearing first, followed by the covariate. The slowest changing variable is labeled " $A$ " by the program, the fastest moving is labeled " $B$." The user may opt to run through the prompted keyboard entry once so that this data entry organization becomes clear. File and DATA statement data are entered in exactly the same order as the keyboard data. A sample data set will be included for those requesting disks.

Output. Output may be directed to the CRT display or to the printer. The data are formatted using PRINT USING statements (for the CoCo and PC versions) and rounded to three-digit accuracy from six (for PCs) or nine (for CoCos).

Availability. A diskette version may be obtained by sending a self-addressed mailer, a 5 1/4-in. floppy disk, and sufficient return postage, along with an indication of the version desired (IBM PC, CoCo, or Apple II+). A listing of any or all of the versions may also be obtained with a self-addressed stamped envelope. Those wishing to convert the program for another system, please indicate the intended system so that a listing for the syntactically closest version may be provided.

\section{REFERENCES}

Cook, T. D., * CAMPBell, D. T. (1979). Quasi-experimentation: Design and analysis issues for field settings. Boston: Houghton Mifflin.

GaLLA, J. P. (1984). Simple analysis of covariance: A BASIC program for microcomputers. Behavior Research Methods, Instruments, \& Computers, 16, 564-565.

HoweLL, D. C. (1982). Statistical methods for psychology. Boston: Duxbury Press.

KIRK, R. E. (1982). Experimental design: Procedures for the behavioral sciences. Monterey, CA: Brooks/Cole.

MEYERS, J. L. (1979). Fundamentals of experimental design. Boston: Allyn \& Bacon.

WINER, B. J. (1971). Statistical principles in experimental design. New York: McGraw-Hill.

(Revision accepted for publication February 18, 1988.) 